\title{
Study on Safety Benchmark Value of Monitoring and Early Warning for Large Section Highway Tunnels
}

\author{
Yuwen Wang ${ }^{1}$, Xiang Yang $\mathrm{Cui}^{3 *}$, Hongyan $\mathrm{Guo}^{2}$ and $\mathrm{Ke} \mathrm{Li}^{2}$ \\ ${ }^{1}$ Guangdong Road and Bridge Construction Development Co., Ltd., Guangzhou, 510000, China \\ ${ }^{2}$ China Merchants Chongqing Communications Technology Research \& Design Institute Co., Ltd, Chongqing,400000, China \\ ${ }^{3}$ Chongqing Jiaotong University, Chongqing 400067, China
}

\begin{abstract}
Taking several tunnels under construction of a highway as the research object, the ultimate displacement of four buried depth sections of 0-50, 50-100, 100-300, 300-500 $\mathrm{m}$ in the surrounding rock of grade III, IV and V is numerically simulated by three-step and seven-step excavation method, middle-wall method, cross-middle-wall method and double-side-wall guide pit method for initial support of large-section highway tunnels. Through analysis, the deformation law of tunnel surrounding rock is obtained: under the same buried depth, the displacement ultimate displacement of the two-sided guide pit method and the cross-middle-wall method is the largest, the middle-wall method is the second, and the three-step seven-step excavation method is the smallest. Through the analysis and collation of the measured data obtained by monitoring and measurement of each construction method in the construction site, the surrounding rock deformation datum values of large-span and large-section tunnel under each construction method are obtained.
\end{abstract}

\section{Introduction}

Tunnel engineering is facing complex underground geological environment. Under the existing technical conditions, it is still difficult to ascertain the accurate geological information in front of the tunnel face. There are certain uncertainties inevitably in tunnel construction. Although the relevant construction technology standards have been formulated in the field of highway tunnel engineering, construction safety accidents still exist [1]. The reason is that the safety management system of field personnel is still imperfect and does not rely on modern monitoring technology. Therefore, it is necessary to establish the surrounding rock deformation benchmark values of large-span and large-cross-section tunnels under various construction methods to establish a practical and efficient management system based on monitoring and measurement information for early warning and feedback. [2-4].

Mashiwei et al. based on the standard displacement limit, the maximum displacement of similar projects and the measured data in the tunnel, according to the method of relative deformation of arch roof relative to the bottom or side wall of the tunnel, analyzed and obtained the established benchmark value of tunnel collapse early warning can meet the needs of tunnel collapse prevention early warning [5]. Chen Wei et al. based on the Jiangluling Carboniferous Shale Tunnel and on-site monitoring data, obtained the deformation datum of the Carboniferous Shale Tunnel under different burial depth by using the $3 \sigma$ statistical method, thus determined the deformation classification and management datum of the surrounding rock under the deep burial of the Jiangluling Tunnel, and made the risk of tunnel collapse to be controlled [6].

Based on the Huiqing Expressway project, this paper combines the geological conditions and construction monitoring data of the tunnels under construction in this project. By means of numerical simulation, the corresponding safety datum values of different surrounding rock depths and construction methods of large section highway tunnels are analyzed and obtained. This conclusion makes the construction monitoring, early warning and construction management of large section tunnels reliable, and the tunnel collapse risk is effectively controlled.

\section{Project Profile}

According to the preliminary design documents, there are 19 tunnels, $7560 \mathrm{~m} / 2$ extra-long tunnels, $6619 \mathrm{~m} / 4$ long tunnels, $4633 \mathrm{~m} / 6$ middle tunnels, $2477 \mathrm{~m} / 7$ short tunnels and $24181 \mathrm{~m}$ long tunnels, accounting for $18.8 \%$ of the total length of the route. The tunnel line is long and the excavation section is large. The standard of double tunnel and six lanes is adopted, and the width of the inner contour of the tunnel reaches $15.59 \mathrm{M}$. Tunnel strata along the line are mainly composed of granite, sandstone and argillaceous shale, which are prone to block collapse during construction.

*Corresponding author's e-mail: 1559039300@qq.com 


\section{Numerical simulation of deformation datum}

The ultimate displacement of tunnel surrounding rock is simulated and calculated by numerical analysis method. Two-dimensional analysis method and elastic-plastic plane finite element method are used to simulate and analyze the supporting system of tunnel. The maximum displacement of surrounding rock under different construction methods, surrounding rock grade and buried depth is determined under the condition of "ultimate displacement" of surrounding rock of large section highway tunnel.

\subsection{Simulating Conditions for Calculating Limit Displacement}

The design parameters of large section highway tunnels are shown in Table 1.

Table 1 Calculating Index of Surrounding Rocks of Class III-V

\begin{tabular}{|c|c|c|c|c|c|}
\hline $\begin{array}{c}\text { Surrounding rock } \\
\text { grade }\end{array}$ & $\begin{array}{l}\text { Gravity } / \gamma \\
(\mathrm{KN} / \mathrm{m} 3) \\
\end{array}$ & $\begin{array}{l}\text { Deformation } \\
\text { modulus/E(GPa) }\end{array}$ & $\begin{array}{c}\text { Poisson } \\
\text { ratio/ } \mu\end{array}$ & Cohesion/C(MPa) & $\begin{array}{c}\text { internal friction } \\
\text { angle } / \varphi\left(^{\circ}\right)\end{array}$ \\
\hline III & $23-25$ & $6-20$ & $0.25-0.3$ & $0.7-1.5$ & $39-50$ \\
\hline IV & $20-23$ & $1.3-6$ & $0.3-0.35$ & $0.2-0.7$ & $27-39$ \\
\hline V & $17-20$ & $1-2$ & $0.35-0.45$ & $0.05-0.2$ & $20-27$ \\
\hline
\end{tabular}

\subsection{Layout of Measuring Points under Four Working Conditions}

In order to better control the construction process and prevent safety accidents in the excavation of large-span

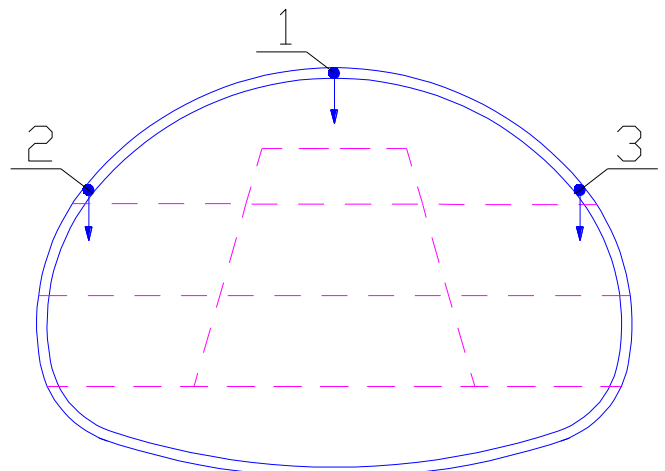

(a) Layout of survey points for three-step and seven-step

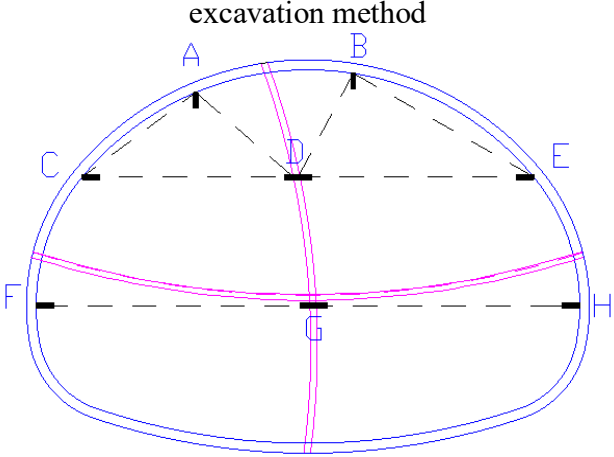

(c) Layout of measuring points by cross-wall method flat tunnels, the safety benchmark value of each section excavation should be worked out. Therefore, the layout of measuring points of four construction method calculation models is shown in Fig. 1

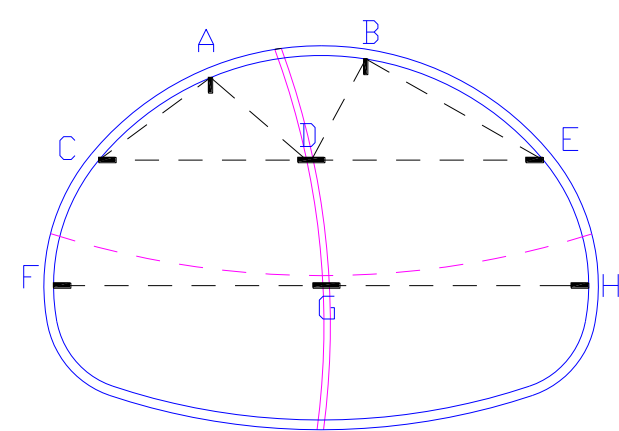

(b) Layout of measuring points in the middle wall method

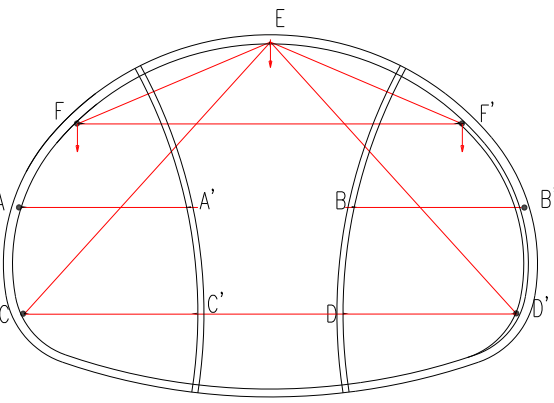

(d) Layout of measuring points by double-sided Guide-Pit method

Fig. 1 Layout of Measuring Points for Four Computing Models of Construction Method

\section{Deformation Safety Datum Value Based on Partial Excavation Construction Process}

In this section, the ultimate displacements of the three-step and seven-step excavation method, the middle-wall method, the cross-middle-wall method and the double-sidewall guide method for the initial support of large cross-section highway tunnels in grade III, IV and $\mathrm{V}$ surrounding rocks, 0-50, 50-100, 100-300, 
300-500 m, are numerically simulated and analyzed. And the following will analyze and collate the measured data obtained by monitoring and measurement of each construction method in the construction site, which not only can effectively avoid the numerical simulation data not conforming to reality, but also can establish a benchmarks value of deformation safety to early warning.

Most of the warning lines are divided into three levels, which are generally divided into normal construction section, strengthening construction section and special measures section. Soft rock takes the maximum of the corresponding range value in the displacement datum table, while hard rock takes the minimum of the corresponding range value, and then takes the $1 / 3$ and $2 / 3$ values of the corresponding range value as the dividing lines of three grades. In this paper, the early warning line is divided into three levels, in which the early warning displacement is $1 / 3$ of the limit displacement value and the allowable displacement is $2 / 3$ of the limit displacement value. This is the safety benchmark value of large cross-section highway tunnel. Early warning displacement is shown in tables 2 to 5 .

Table 2 Relative displacement (\%) of early warning for large cross-section highway tunnels (three steps and seven steps excavation method)

\begin{tabular}{|c|c|c|c|c|}
\hline \multirow{2}{*}{$\begin{array}{l}\text { Surrounding rock } \\
\text { grade }\end{array}$} & \multicolumn{4}{|c|}{ Depth } \\
\hline & $\leq 50 \mathrm{~m}$ & $\leq 100 \mathrm{~m}$ & $\leq 300 \mathrm{~m}$ & $\leq 500 \mathrm{~m}$ \\
\hline \multicolumn{5}{|c|}{ Relative convergence of vault settlement } \\
\hline III & $0.004 \sim 0.034$ & $0.007 \sim 0.062$ & $0.008 \sim 0.116$ & $0.016 \sim 0.176$ \\
\hline IV & $0.013 \sim 0.0504$ & $0.013 \sim 0.076$ & $0.018 \sim 0.127$ & $0.158 \sim 0.204$ \\
\hline \multicolumn{5}{|c|}{ Relative convergence of arch foot } \\
\hline III & $0.003 \sim 0.031$ & $0.005 \sim 0.058$ & $0.009 \sim 0.113$ & $0.044 \sim 0.163$ \\
\hline IV & $0.009 \sim 0.051$ & $0.012 \sim 0.077$ & $0.023 \sim 0.131$ & $0.134 \sim 0.165$ \\
\hline \multicolumn{5}{|c|}{ Relative convergence of waist and wall } \\
\hline III & $0.03 \sim 0.040$ & $0.005 \sim 0.077$ & $0.009 \sim 0.139$ & $0.011 \sim 0.196$ \\
\hline IV & $0.009 \sim 0.053$ & $0.021 \sim 0.09$ & $0.085 \sim 0.152$ & $0.159 \sim 0.212$ \\
\hline
\end{tabular}

Table 3 Relative displacement (\%) of early warning for large cross-section highway tunnel initial support (cross-middle-wall method)

\begin{tabular}{|c|c|c|c|c|}
\hline \multirow{2}{*}{$\begin{array}{l}\text { Surrounding rock } \\
\text { grade }\end{array}$} & \multicolumn{4}{|c|}{ Depth } \\
\hline & $\leq 50 \mathrm{~m}$ & $\leq 100 \mathrm{~m}$ & $\leq 300 \mathrm{~m}$ & $\leq 500 \mathrm{~m}$ \\
\hline \multicolumn{5}{|c|}{ Relative convergence of vault settlement } \\
\hline IV & $0.013 \sim 0.055$ & $0.028 \sim 0.094$ & $0.027 \sim 0.042$ & $0.026 \sim 0.056$ \\
\hline $\mathrm{V}$ & $0.028 \sim 0.058$ & $0.064 \sim 0.096$ & $0.219 \sim 0.25$ & $0.378 \sim 0.432$ \\
\hline \multicolumn{5}{|c|}{ Relative convergence of arch foot } \\
\hline IV & $0.015 \sim 0.124$ & $0.031 \sim 0.11$ & $0.032 \sim 0.048$ & $0.029 \sim 0.066$ \\
\hline $\mathrm{V}$ & $0.033 \sim 0.060$ & $0.081 \sim 0.112$ & $0.299 \sim 0.352$ & $0.525 \sim 0.62$ \\
\hline \multicolumn{5}{|c|}{ Relative convergence of waist and wall } \\
\hline IV & $0.009 \sim 0.049$ & $0.017 \sim 0.80$ & $0.018 \sim 0.026$ & $0.017 \sim 0.034$ \\
\hline $\mathrm{V}$ & $0.019 \sim 0.049$ & $0.041 \sim 0.090$ & $0.144 \sim 0.168$ & $0.251 \sim 0.295$ \\
\hline
\end{tabular}

Table 4 Relative displacement (\%) of early warning for large cross-section highway tunnel initial support (middle wall method)

\begin{tabular}{ccccc}
\hline \multirow{2}{*}{$\begin{array}{c}\text { Surrounding rock } \\
\text { grade }\end{array}$} & \multicolumn{5}{c}{ Depth } \\
\cline { 2 - 5 } & \multicolumn{5}{c}{$\leq 0 \mathrm{~m}$} & $\leq 100 \mathrm{~m}$ & $\leq 300 \mathrm{~m}$ & $\leq 500 \mathrm{~m}$ \\
\hline \multicolumn{5}{c}{ Relative convergence of vault settlement } \\
\hline $\mathrm{IV}$ & $0.020 \sim 0.059$ & $0.028 \sim 0.101$ & $0.010 \sim 0.128$ & $0.178 \sim 0.232$ \\
\hline $\mathrm{V}$ & $0.028 \sim 0.058$ & $0.064 \sim 0.097$ & $0.225 \sim 0.257$ & $0.388 \sim 0.445$ \\
\hline
\end{tabular}




\begin{tabular}{ccccc}
\hline \multicolumn{5}{c}{ Relative convergence of arch foot } \\
\hline $\mathrm{IV}$ & $0.023 \sim 0.093$ & $0.031 \sim 0.138$ & $0.11 \sim 0.146$ & $0.212 \sim 0.269$ \\
\hline $\mathrm{V}$ & $0.33 \sim 0.089$ & $0.079 \sim 0.118$ & $0.3 \sim 0.346$ & $0.512 \sim 0.593$ \\
\hline \multicolumn{5}{c}{ Relative convergence of waist and wall } \\
\hline $\mathrm{IV}$ & $0.013 \sim 0.064$ & $0.02 \sim 0.084$ & $0.075 \sim 0.10$ & $0.141 \sim 0.185$ \\
\hline $\mathrm{V}$ & $0.025 \sim 0.055$ & $0.061 \sim 0.074$ & $0.229 \sim 0.27$ & $0.405 \sim 0.479$ \\
\hline
\end{tabular}

Table 5 Relative displacement (\%) of early warning for initial support of large cross-section highway tunnels (double-sided heading method)

\begin{tabular}{|c|c|c|c|c|}
\hline \multirow{2}{*}{$\begin{array}{l}\text { Surrounding rock } \\
\text { grade }\end{array}$} & \multicolumn{4}{|c|}{ Depth } \\
\hline & $\leq 50 \mathrm{~m}$ & $\leq 100 \mathrm{~m}$ & $\leq 300 \mathrm{~m}$ & $\leq 500 \mathrm{~m}$ \\
\hline \multicolumn{5}{|c|}{ Relative convergence of vault settlement } \\
\hline IV & $0.012 \sim 0.056$ & $0.027 \sim 0.096$ & $0.098 \sim 0.127$ & $0.176 \sim 0.228$ \\
\hline $\mathrm{V}$ & $0.026 \sim 0.065$ & $0.062 \sim 0.108$ & $0.215 \sim 0.249$ & $0.39 \sim 0.445$ \\
\hline \multicolumn{5}{|c|}{ Relative convergence of arch foot } \\
\hline IV & $0.01 \sim 0.065$ & $0.021 \sim 0.102$ & $0.078 \sim 0.098$ & $0.139 \sim 0.174$ \\
\hline $\mathrm{V}$ & $0.021 \sim 0.071$ & $0.048 \sim 0.094$ & $0.169 \sim 0.192$ & $0.333 \sim 0.625$ \\
\hline \multicolumn{5}{|c|}{ Relative convergence of waist and wall } \\
\hline IV & $0.008 \sim 0.057$ & $0.017 \sim 0.085$ & $0.06 \sim 0.075$ & $0.106 \sim 0.132$ \\
\hline $\mathrm{V}$ & $0.018 \sim 0.0504$ & $0.039 \sim 0.08$ & $0.130 \sim 0.146$ & $0.223 \sim 0.252$ \\
\hline
\end{tabular}

\section{Conclusion}

The ultimate displacements of the three-step and seven-step excavation method, the middle-wall method, the cross-middle-wall method and the double-side wall guide method for the initial support of large cross-section highway tunnels in grade III, IV, V surrounding rocks, 0-50, 50-100, 100-300 and 300-500 m buried depth sections are numerically simulated and analyzed by using the stratum structure method and the strength reduction method, respectively:

(1) Under the same construction method, with the increase of burial depth, the ultimate relative displacement increases, while with the decrease of surrounding rock grade, the ultimate relative displacement decreases.

(2) Under the same burial depth, the influence of four construction methods on the deformation of surrounding rock is as follows: the displacement limit displacement of the double-sided guide pit method and the cross-middle-wall method is the largest, the middle-wall method is the second, and the three-step seven-step excavation method is the smallest. Under the same level of surrounding rock, there is no obvious limit for the ultimate relative displacement of adjacent buried depth.

(3) Based on the analysis and collation of the measured data obtained from monitoring and measurement of each construction method in the construction site, the early warning safety benchmark values of large cross-section highway tunnel initial support with different construction methods, surrounding rock levels and buried depth are established.

\section{Acknowledgments}

National Key Research and Development Plan of China (2017YFC08060010, 2017YFC08060003), This work is financially supported by Security Science and Technology Innovation Project for Social Undertakings and People's Livelihood Guarantee in Chongqing, China (cstc2017shmsA30010), Project of the National Natural Science Foundation of China (41601574).

\section{Reference}

1. Yan G.M., Shen Y.S., Gao B., Zheng Q., Fan K.X., Huang H.F. (2019) Model test of sublevel joints crossing stick-slip faults [J/OL]. Geotechnical Mechanics, (11): 1-9.

2. Liu B., Yang W.H. (2019) Three-dimensional settlement prediction model of tunnel excavation considering time effect and its application $[\mathrm{J} / \mathrm{OL}]$. Journal of Mining Science, (05): 1-10.

3. Liang D., Jin H., Xiao J H., Zhou S.H. (2019) The influence of lateral pressure loss on the stress and deformation of shield tunnel in soft soil area [J]. Engineering Mechanics, 36 (05): 148-156+175.

4. Li J., Shao S.J., She F.T., Wang Y.X. (2019) Application of sand well immersion test in evaluation of foundation collapsibility deformation of loess tunnel [J/OL]. Journal of Rock Mechanics and Engineering: 38:1-8. 
5. Ma S.W., Han X.J., Liao K., Du J. (2014) Study on the real-time monitoring and early warning standard for collapse prevention of large-section weak surrounding rock tunnel [J]. Journal of Railway Engineering, 31 (09): 88-92.

6. Chen W., Cao P., Guo H.Y., Hu X.B. (2018) Study on Deformation Safety Criteria of Carbonaceous Shale Tunnel in Typical Highway $[\mathrm{J}]$. Journal of Underground Space and Engineering, 14 (S2): 752-756+762. 